\title{
Methamphetamine: A molecular and pathological exacerbate of HIV neurocognitive disorder
}

\author{
Shahid Salaria* \\ Eliezer Masliah* \\ Gursharan Chana* \\ Ian Everall* \\ * Department of Psychiatry, \\ University of California, San Diego \\ USA
}

\begin{abstract}
The use of the recreational drug methamphetamine is becoming more widespread, and it is accompanied by unsafe sexual behaviours that increase the transmission of the human immunodeficiency virus (HIV). This article reviews the available literature of the effect of methamphetamine on the HIV infected brain, and in particular the molecular disturbances and neuropathology associated within this cohort. Our molecular research indicates that methamphetamine and HIV have a synergistic pathological impact on neuronal cell injury and death, which may be mediated by an upregulation of interferon inducible genes observed within this group, thereby contributing to the neurocognitive deficits observed in clinical populations of HIV infected methamphetamine abusers.
\end{abstract}

\section{Epidemiology of HIV infection and AIDS}

Since its initial description amongst a few previously healthy young homosexual men in Los Angeles in 1981, acquired immunodeficiency syndrome (AIDS) has evolved to become a global pandemic, with the World Health Organisation (WHO) estimating that the total number of people infected with HIV rose in 2004 to its highest level ever: an estimated 39.4 million. This figure includes the 4.9 million people who became infected with HIV in 2004. Worldwide there have been 3.1 million deaths from AIDS in 2004, with the death toll rising daily. In Western and Central Europe, the estimated figure of those infected with the virus was 610,000 (Joint United Nations Program on HIV/ AIDS, 2004).

\section{HIV Neuroinvasion}

It appears that the main cell types infected by HIV in the central nervous system 
(CNS) and in particular the brain are microglia and macrophages (Clayton et al. 1990, Gonzalez-Scarano \& Martin-Garcia 2005, Fischer-Smith et al. 2004). There is a growing body of evidence which suggests that in addition to these two cell types there are other cells within the brain such as astrocytes, which can be infected (BrackWerner 1999, Bagasra et al. 1996, TrilloPazos et al. 2003). However, if astrocytes are infected they are unable to sustain viral replication and are limited to producing early viral regulatory proteins only, and as such, it has been challenging to establish the direct link between astrocytes and neuropathogenesis of HIV. Infection of the CNS can be proven in about $80 \%$ of HIVinfected individuals (Speth et al. 2005). The virus enters the brain after systemic infection of CD4+ lymphocytes (An et al. 1999). $\mathrm{CD}^{+}{ }^{+}$together with chemokine receptors CXCR4 and CCR5 are the main membrane bound receptors that facilitate attachment of the virus and fusion of viral and cellular membranes, leading to entry of the virus into the cell; for review, see (Zaitseva et al. 2003). These cells migrate across the blood brain barrier in order to replenish the pools of macrophages (Gonzalez-Scarano \& Martin-Garcia 2005). In the process of differentiating into macrophages, the virus-infected monocytes encounter mainly perivascular macrophages and microglia, which become infected and contribute to the increasing viral load. The HIV envelope glycoproteins that are expressed at the surface of infected cells, mediate cell to cell fusion of macrophages and microglia, resulting in the formation of multinucleated giant cells (MNGC) (Sharer et al. 1985). MGNCs, as well as functioning as cellular sites of virus production, also serve as a morphological hallmark of HIV encephalitis (HIVE).

\section{Neuropathological and Clinical Aspects of HIV infection}

The neuropathological consequences of HIV brain infection are well characterized and include neuronal loss (Everall et al. 1993, Everall et al. 1991), dendritic and synaptic damage (Masliah et al. 1992, Everall et al. 1999), as well as astrocytosis and microgliosis (Figure 1) (Budka 1993). Mechanisms by which neurodegeneration occur are still being elucidated but are postulated to include both direct and indirect avenues. Numerous studies have demonstrated neurotoxicity induced directly by various viral proteins, including the envelope protein, GP120 (Lipton et al. 1991) and regulatory proteins TAT (Nath et al. 2000) and nef (Trillo-Pazos et al. 2000). For GP120 and TAT, excitotoxicity has been implicated (Lipton 1994, Nath et al. 1995). However, infection of the brain is also associated with prolonged cytokine dysregulation, which may be a potential mediator of indirect virally mediated neurodegeneration (Corasaniti et al. 2001, Ensoli et al. 1999). Many other putative neurotoxic pathways have been proposed and all of these avenues of neurotoxicity are likely to be interactive and not acting in isolation (Fine et al. 1996, Vitkovic \& Tardieu 1998).

Clinically, affected individuals can suffer a range of neuropsychiatric disorders from mild cognitive impairment to severe HIV associated dementia (HAD). The essential features of HAD are marked cognitive impairments usually accompanied by motor dysfunction and behavioural changes. Cognitive impairment is characterised by mental slowness, forgetfulness, and poor concentration. Behavioural changes may include apathy, lethargy and 
diminished spontaneity and emotional responses. Motor symptoms include loss of fine motor control, clumsiness, unsteady gait and tremor. Clinico-pathological studies have to date identified dendritic and synaptic damage, and selective neuronal loss as factors mediating cognitive impairment (Asare et al. 1996) as well as being related to rising brain viral load (Everall $e t$ al. 1999).
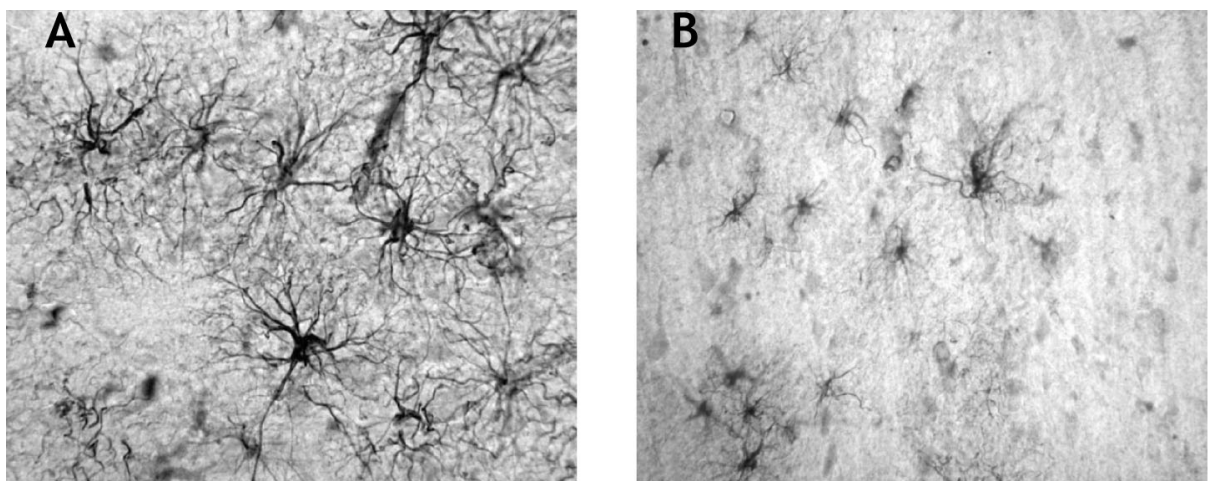

Figure 1. Immunoperoxidase staining for glial fibrillary acidic protein (GFAP) in post-mortem frontal cortex. Increased cellular GFAP staining is observed in the advanced HIV+ disease demonstrating inflammation (A) compared to non-HIV infected control case (B). (Magnification x1000).

\section{The Emergence of Methamphetamine as an HIV Co-factor}

\section{Methamphetamine Neurotoxicity}

Attempts to understand the mechanisms mediating HIV neurotoxicity have been further complicated with the findings that cofactors, such as drugs of abuse may exacerbate HIV neurodegeneration. The stimulant drug methamphetamine (MA) is a cationic lipophilic molecule readily capable of crossing the blood brain barrier and therefore has a potent action on the CNS. MA induces the release of dopamine (DA) from pre-synaptic terminals and causes the decrease in the number of DA transporters (Westphalen \& Stadlin 2000, Stadlin et al. 1998). Clinically, MA has been found to reduce fatigue, increase alertness and cause a sense of confidence and euphoria in the user (Hanson et al. 2004). In-vitro and human neuroimaging studies, have shown MA to be detrimental to the dopaminergic (DA) metabolism (Davidson et al. 2005, Volkow et al. 2004, Vollm et al. 2004). In addition, glutamatergic cells in the hippocampus and neocortex (Ohmori et al. 1996, Marshall et al. 1993, Bae et al. 2005), serotonergic cells in the raphe nucleus, and GABAergic interneuron's in the neocortex, basal ganglia and hippocampus (Jernigan et al. 2005, Hanson et al. 2004) have all been shown to be adversely affected by MA. This MA induced neurotoxicity may in part be related to the generation of reactive oxygen or nitrogen species (Davidson et al. 2001). For example, the acute administration of MA to rodents resulted in production of oxidative stress as demonstrated by reduced glutathione and increased oxidized glutathione levels in the rat striatum and pre- 
frontal cortex (Acikgoz et al. 1998, Harold et al. 2000). MA induced oxidative stress in mice has also been observed to activate redox-responsive transcription factors such as activator protein-1 (AP-1) and cAMPresponsive element binding protein (CREB) (Lee et al. 1999).

\section{Cognitive Decline in HIV Infected Methamphetamine Using Population}

The HIV infected drug user group is the fastest growing population living with HIV in Western Europe and the USA (Gibson et al. 2002, Nath et al. 2001). In recent years, the HIV infected MA using population has contributed significantly to this trend, with studies suggesting that MA use presents a serious problem due to its relationship with the high risk sexual behaviours associated with HIV transmission (Urbina \& Jones 2004, Chesney et al. 1998). While the separate neuropsychological effects of either HIV or drug abuse is well documented, less is known about these factors in combination. At the HIV neurobehavioural research centre (HNRC), University of California, San Diego, studies have demonstrated that the combination of HIV and MA use is associated with excess neurocognitive disorder, highlighting that individuals with both HIV and a current history of MA use exhibit the highest rates of cognitive impairment when compared to controls and non MA using HIV infected subjects. Alongside this, those with HIV and a current history of MA use are more likely to show continued cognitive decline at 1-4 year follow up (Rippeth et al. 2004). A recent MRI study examining the effects of MA use and HIV on cerebral morphology indicate that there is an additive significant brain structure alterations associated with both HIV and MA use. There were distinct regional patterns of changes associated with either HIV or MA. These changes were mainly atrophy but for MA they also included regional caudate volume enlargement, probably due to an increase in the neuropil. Certain cortical regions were doubly affected by both HIV and MA (Jernigan et al. 2005).

\section{Patterns of Neurodegeneration}

An emerging synergism between HIV and MA is the neurotoxic effects of these two agents together on the CNS. Clinically, as stated above MA use worsens HIV neurocognitive deficits (Rippeth et al. 2004) and it can amplify brain viral load (Gurwell et al. 2001, Maragos et al. 2002). As previously mentioned, the neurotoxic effects of MA on the brain monoamine systems are well characterised and can result in neuronal loss, loss of dendritic processes and decreases in synaptic densities (Phillips et al. 2000). Similarly, HIV infection has been shown to mediate toxic effects in selective neuronal populations (Masliah et al. 1994). These effects also include neuronal damage, loss of dendritic processes and synaptic simplification (Masliah et al. 1994, Wiley et al. 1991, Everall et al. 1999). Since HIV and MA are both capable of causing degeneration of DAergic neurons as well as other neuronal cell types, recent studies have focused on understanding the neuropathology of the HIV infected, MA using population. In our analysis of neurodegeneration we assessed the effect of HIV and MA on all neurons, as visualized with the neuronal dendritic marker, microtubule associate protein-2, as well as markers of specific interneuronal and pyramidal neuronal populations which selectively express the calcium binding proteins, Calbindin (CB) or Parvalbumin $(\mathrm{PV})$. We observed a an extensive 
loss of CB interneurons in the neocortex (Figure 2), accompanied by aberrant sprouting and axonal damage in HIV infected MA using brain tissue, compared to HIV infected and HIVE tissue (Langford et al. 2003). It has previously been demonstrated that $\mathrm{CB}$ interneurons regulate the firing rate of pyramidal neurons and contribute to cognitive function (Hof et al. 1999, Blatow et al.
2003). A decrease in the numbers of $C B$ immunopositive neurons may therefore partially account for the diminished neurocognitive functions exhibited by HIV infected MA using patients. The molecular mechanisms through which MA and HIV interact to injure neuronal populations is unclear, however common paths of convergence are beginning to be elucidated.
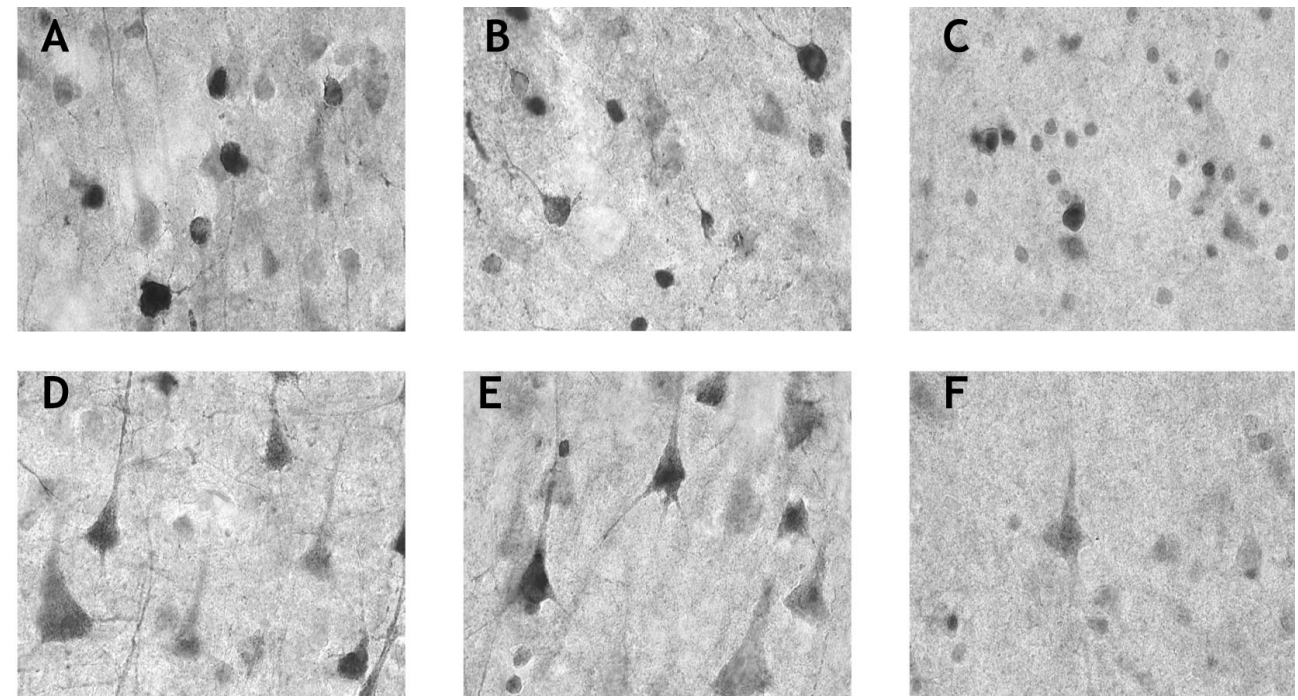

Figure 2. Immunostaining for Calbindin in the frontal cortex of patients with HIV, HIVE and HIVE plus MA use. Images (A-C) are interneurons; (D-F) are pyramidal neurons. Qualitative reductions in Calbindin immunopositive neurons can be seen in HIVE and even more so in the HIVE plus MA when compared to the HIV $(+)$ sections. (Magnification $\mathrm{x} 1000)$.

\section{Synergistic Molecular Pathways of HIV and MA Neurodegeneration}

The emergence of microarray analysis has facilitated the ability to obtain a comprehensive picture of gene expression changes associated with HIV infection and MA use in order to provide clues to the molecular mechanism by which MA exacerbates HIV neurodegeneration. In order to evaluate the contribution of gene expression alterations to the neurodegenerative process in the HIV infected and MA using population, we undertook a high-density oligonucleotide array study using RNA from the frontal cortex of this patient group, and the Affymetrix Human U95Av2 GeneChip. We initially observed that there were significant alterations in gene expression due to the presence of HIVE in our samples. Of the 12,695 genes analysed, 74 were significantly downregulated and 59 were significantly upregulated in our HIVE group compared to 
our controls (Masliah et al. 2004). Upon further analysis, we observed that the group of genes induced by Interferons (IFI) were the most significantly elevated, with a 2fold increase in the HIVE group, and a 3fold increase in our HIV infected MA using sub-group when compared to our control cases (Everall et al. 2005). In order to further qualify and validate these findings, we conducted immunohistochemistry staining on brain tissue followed by optical density counts for two of the upregulated proteins, Interferon stimulated gene 15 (ISG15) and signal transducer and activator of transcription (STAT1). Both these qualitative and quantitative analysis showed significant upregulation of the two proteins in the HIV infected MA using group (Everall et al. 2005). In recent years more than 300 IFN genes have been identified (Der et al. 1998), and the proteins encoded by these genes have a significant role in the antiviral, immunomodulatory, anti-angiogenic and anti proliferative effects (Stark et al. 1998). INF genes such as ISG15 and those involved in the cascade such as STAT1, may not only mediate the antiviral effects, but they may also be involved in promoting proapoptotic cascades that can result in neurodegeneration (Chawla-Sarkar et al. 2003, Chawla-Sarkar et al. 2001, Jung et al. 2005). Our studies have shown that both HIVE and MA abuse can lead to a synergistic effect in upregulating IFN inducible genes. We have also shown that in the brains of patients with HIVE, the elevated expression of IFN inducible genes correlates with the severity of cognitive impairments (Masliah et al. 2004).

In summary, we have observed that MA use in HIV infected individuals is associated with greater cognitive decline, a decrease in the number of Calbindin containing neurons, (in addition to other selective neu- ropathology), and a significant up-regulation of IFN inducible genes. Further studies are required to elucidate whether these genes are indeed the molecular substrate to the extra neurodegenerative burden, which could contribute to the excess cognitive decline observed in this increasing population.

\section{References}

Acikgoz O, Gonenc S, Kayatekin BM, Uysal N, Pekcetin C, Semin I et al. Methamphetamine causes lipid peroxidation and an increase in superoxide dismutase activity in the rat striatum. Brain Res 1998; 813: 200-202.

An SF, Groves M, Gray F, Scaravilli F. Early entry and widespread cellular involvement of HIV-1 DNA in brains of HIV-1 positive asymptomatic individuals. J Neuropath Exp Neur 1999; 58: 1156-1162.

Asare E, Dunn G, Glass J, McArthur J, Luthert P, Lantos $\mathrm{P}$ et al. Neuronal pattern correlates with the severity of human immunodeficiency virus-associated dementia complex - Usefulness of spatial pattern analysis in clinicopathological studies. Am J Pathol 1996; 148: 31-38.

Bae SC, Lyoo IK, Sung YH, Yoo J, Chung A, Yoon SJ et al. Increased white matter hyperintensities in male methamphetamine abusers. Drug Alcohol Depend. (In press) available from URL: http://dx.doi.org/doi:10.1016/ j.drugalcdep.2005.05.016

Bagasra O, Lavi E, Bobroski L, Khalili K, Pestaner JP, Tawadros R. Cellular reservoirs of HIV-1 in the central nervous system of infected individuals: Identification by the combination of in situ polymerase chain reaction and immunohistochemistry. Aids 1996; 10: 573-585.

Blatow M, Caputi A, Burnashev N, Monyer H, Rozov A. $\mathrm{Ca} 2+$ buffer saturation underlies paired pulse facilitation in Calbindin-D28k-containing terminals. Neuron 2003; 38: 79-88.

Brack-Werner R. Astrocytes: HIV cellular reservoirs and important participants in neuropathogenesis. Aids 1999; 13: 1-22.

Budka H. Pathology and Pathogenesis of Brain-Damage in HIV-Infection. J Neurochem 1993; 61: S62.

Chawla-Sarkar M, Leaman DW, Borden EC. Preferential induction of apoptosis by interferon (IFN)-beta compared with IFN-alpha 2: Correlation with TRAIL/Apo2L 
induction in melanoma cell lines. Clin Cancer Res 2001; 7 : 1821-1831.

Chawla-Sarkar M, Lindner DJ, Liu YF, Williams B, Sen GC, Silverman RH, Borden EC. Apoptosis and interferons: Role of interferon-stimulated genes as mediators of apoptosis. Apoptosis 2003; 8: 237-249.

Chesney MA, Barrett DC, Stall R. Histories of substance use and risk behavior: Precursors to HIV seroconversion in homosexual men. Am J Public Health 1998; 88: 113-116.

Clayton LK, Sieh M, Reinherz EL. CD4 Interactions with Its Ligands HIV GP120 and Class-II MHC. Aids Res Hum Retrov 1990; 6: 117.

Corasaniti MT, Piccirilli S, Paoletti A, Nistico R, Stringaro A, Malorni W et al. Evidence that the HIV-1 coat protein GP120 causes neuronal apoptosis in the neocortex of rat via a mechanism involving CXCR4 chemokine receptor. Neurosci Lett 2001; 312: 67-70.

Davidson C, Gow AJ, Lee TH, Ellinwood EH. Methamphetamine neurotoxicity: necrotic and apoptotic mechanisms and relevance to human abuse and treatment. Brain Res Reviews 2001; 36: 1-22.

Davidson C, Lee TH, Ellinwood EH. Acute and chronic continuous methamphetamine have different long-term behavioral and neurochemical consequences. Neurochem Int 2005; 46: 189-203.

Der SD, Zhou AM, Williams BRG, Silverman RH. Identification of genes differentially regulated by interferon alpha, beta, or gamma using oligonucleotide arrays. Proc Natl Acad Sci USA 1998; 95: 15623-15628.

Ensoli F, Fiorelli V, DeCristofaro M, Muratori DS, Novi A, Vannelli B et al. Inflammatory cytokines and HIV-1associated neurodegeneration: Oncostatin-M produced by mononuclear cells from HIV-1-infected individuals induces apoptosis of primary neurons. J Immunol 1999; 162: 6268-6277.

Everall IP, Heaton RK, Marcotte TD, Ellis RJ, McCutchan JA, Atkinson JH et al. Cortical synaptic density is reduced in mild to moderate human immunodeficiency virus neurocognitive disorder. HNRC Group. HIV Neurobehavioral Research Center. Brain Pathol 1999; 9: 209-217.

Everall IP, Luthert PJ, Lantos PL. Neuronal loss in the frontal cortex in HIV infection. Lancet 1991; 337: 11191121.

Everall IP, Luthert PJ, Lantos PL. Neuronal number and volume alterations in the neocortex of HIV infected individuals. J Neurol Neurosurg Psychiatry 1993; 56: 481-486.

Everall IP, Salaria S, Roberts E, Corbeil L, Sasik R, Fox $\mathrm{H}$ et al. Methamphetamine Stimulates Interferon Inducible Genes in HIV Infected Brains. J Neuroimmunol (in press).
Fine SM, Angel RA, Perry SW, Epstein LG, Rothstein JD, Dewhurst S et al. Tumor necrosis factor alpha inhibits glutamate uptake by primary human astrocytes - Implications for pathogenesis of HIV-1 dementia. J Biol Chem 1996; 271: 15303-15306.

Fischer-Smith T, Croul S, Adeniyi A, Rybicka K, Morgello S, Khalili K et al. Macrophage/microglial accumulation and proliferating cell nuclear antigen expression in the central nervous system in human immunodeficiency virus encephalopathy. Am J Pathol 2004; 164: 2089-2099.

Gibson DR, Leamon MH, Flynn N. Epidemiology and public health consequences of methamphetamine use in California's Central Valley. J Psychoactive Drugs 2002; 34: 313-319.

Gonzalez-Scarano F, Martin-Garcia J. The neuropathogenesis of AIDS. Nat Rev Immunol 2005; 5: 69-81.

Gurwell JA, Nath A, Sun Q, Zhang J, Martin KM, Chen Y et al. Synergistic neurotoxicity of opioids and human immunodeficiency virus-1 Tat protein in striatal neurons in vitro. Neuroscience 2001; 102: 555-563.

Hanson GR, Rau KS, Fleckenstein AE. The methamphetarnine experience: a NIDA partnership. Neuropharmacology 2004; 47: 92-100.

Harold C, Wallace T, Friedman R, Gudelsky G, Yamamoto B. Methamphetamine selectively alters brain glutathione. Eur J Pharmacol 2000; 400: 99-102.

Hof PR, Glezer II, Conde F, Flagg RA, Rubin MB, Nimchinsky EA et al. Cellular distribution of the calcium binding proteins Parvalbumin, Calbindin, and Calretinin in the neocortex of mammals: phylogenetic and developmental patterns. J Chem Neuroanat 1999; 16: 77-116.

Jernigan TL, Gamst AC, Archibald SL, Fennema-Notestine C, Mindt MR, Marcotte TL et al. Effects of Methamphetamine Dependence and HIV Infection on Cerebral Morphology. Am J Psychiatry 2005; 162: 1461-1472.

Jung DY, Lee H, Suk K. Pro-apoptotic activity of Nmyc in activation-induced cell death of microglia. $\mathrm{J} \mathrm{Neu}$ rochem 2005; 94: 249-256.

Langford D, Adame A, Grigorian A, Grant I, McCutchan JA, Ellis RJ et al. Patterns of selective neuronal damage in methamphetamine-user AIDS patients. $J$ Acquir Immune Defic Syndr 2003; 34: 467-474.

Lee Y, Hamamura T, Ohashi K, Fujiwara Y, Kuroda S. The effect of lithium on methamphetamine-induced regional Fos protein expression in the rat brain. Neuroreport 1999; 10: 895-900.

Lipton SA. HIV Coat Protein GP120 Induces Soluble Neurotoxins in Culture-Medium. Neurosci Res Commun 1994; 15: 31-37. 
Lipton SA, Sucher NJ, Kaiser PK, Dreyer EB. Synergistic Effects of HIV Coat Protein and NMDA ReceptorMediated Neurotoxicity. Neuron 1991; 7: 111-118.

Maragos WF, Young KL, Turchan JT, Guseva M, Pauly JR, Nath A et al. Human immunodeficiency virus-1 TAT protein and methamphetamine interact synergistically to impair striatal dopaminergic function. J Neurochem 2002; 83: $955-963$.

Marshall JF, Odell SJ, Weihmuller FB. Dopamine-Glutamate Interactions in Methamphetamine-Induced Neurotoxicity. J Neural Transm Gen Sect 1993; 91: 241-254.

Masliah E, Achim CL, Ge N, De Teresa R, Wiley CA. Cellular neuropathology in HIV encephalitis. Res Publ Assoc Res Nerv Ment Dis 1994; 72: 119-131.

Masliah E, Ge N, Morey M, De Teresa R, Terry RD, Wiley CA. Cortical dendritic pathology in human immunodeficiency virus encephalitis. Lab Invest 1992; 66: 285-291.

Masliah E, Roberts ES, Langford D, Everall I, Crews L, Adame A et al. Patterns of gene dysregulation in the frontal cortex of patients with HIV encephalitis. $J \mathrm{Neu}$ roimmunol 2004; 157: 163-175.

Nath A, Haughey NJ, Jones M, Anderson C, Bell JE, Geiger JD. Synergistic neurotoxicity by human immunodeficiency virus proteins TAT and GP120: Protection by memantine. Ann Neurol 2000; 47: 186-194.

Nath A, Maragos WF, Avison MJ, Schmitt FA, Berger JR. Acceleration of HIV dementia with methamphetamine and cocaine. J Neurovirol 2001; 7: 66-71.

Nath A, Padua RA, Geiger JD. HIV-1 Coat Protein GP120-Induced Increases in Levels of Intrasynaptosomal Calcium. Brain Res 1995; 678: 200-206.

Ohmori T, Abekawa T, Koyama T. The role of glutamate in the neurotoxic effects of methamphetamine. Ann NY Acad Sci 1996; 801: 315-326.

Phillips TR, Billaud JN, Henriksen SJ. Methamphetamine and HIV-1: potential interactions and the use of the FIV/CAT model. J Psychopharmacol 2000; 14: 244-250.

Rippeth JD, Heaton RK, Carey CL, Marcotte TD, Moore DJ, Gonzalez R et al. Methamphetamine dependence increases risk of neuropsychological impairment in HIV infected persons. J Int Neuropsychol Soc 2004; 10: 1-14.

Sharer LR, Cho ES, Epstein LG. Multinucleated GiantCells and HTLV-III in AIDS Encephalopathy. Hum Pathol 1985; 16(8): 760.

Speth C, Dierich MR, Sopper S. HIV-infection of the central nervous system: the tightrope walk of innate immunity. Mol Immunol 2005; 42: 213-228.

Stadlin A, Lau JWS, Szeto YK. A selective regional response of cultured astrocytes to methamphetamine. Ann NY Acad Sci 1998; 844: 108-121.
Stark GR, Kerr IM, Williams BRG, Silverman RH, Schreiber RD. How cells respond to interferons. Annu Rev Biochem 1998; 67: 227-264.

Trillo-Pazos G, Diamanturos A, Rislove L, Menza T, Chao W, Belem P et al. Detection of HIV-1 DNA in microglia/macrophages, astrocytes and neurons isolated from brain tissue with HIV-1 encephalitis by laser capture microdissection. Brain Pathol 2003; 13: 144-154.

Trillo-Pazos G., McFarlane-Abdulla E, Campbell IC, Pilkington GJ, Everall IP. Recombinant nef HIV-IIIB protein is toxic to human neurons in culture. Brain Res 2000; 864: 315-326.

Urbina A, Jones K. Crystal methamphetamine, its analogues, and HIV infection: Medical and psychiatric aspects of a new epidemic. Clin Infect Dis 2004; 38: 890-894.

Vitkovic L, Tardieu M. Neuropathogenesis of HIV-1 infection. Outstanding questions. C R Acad Sci III 1998; 321: 1015-1021.

Volkow ND, Fowler JS, Wang GJ, Swanson JM. Dopamine in drug abuse and addiction: results from imaging studies and treatment implications. Mol Psychiatry 2004; 9: 557-569.

Vollm BA, de Araujo IE, Cowen PJ, Rolls ET, Kringelbach ML, Smith KA et al. Methamphetamine activates reward circuitry in drug naive human subjects. Neuropsychopharmacology 2004; 29: 1715-1722.

Westphalen RI, Stadlin A. Dopamine uptake blockers nullify methamphetamine-induced decrease in dopamine uptake and plasma membrane potential in rat striatal synaptosomes. Ann N Y Acad Sci 2000; 914: 187-193.

Wiley CA, Masliah E, Morey M, Lemere C, De Teresa $\mathrm{R}$, Grafe M et al. Neocortical Damage During HIV-Infection. Ann Neurol 1991; 29: 651-657.

Zaitseva M, Peden K, Golding H. HIV coreceptors: role of structure, posttranslational modifications, and internalization in viral-cell fusion and as targets for entry inhibitors. Biochim Biophys Acta 2003; 1614(1): 51-61.

Adress of correspondence:

Shahid Salaria

Department of Psychiatry

University of California San Diego

9500 Gilman Drive, La Jolla, CA 92093-0603

Tel: 1- 858 - 5340463

Email: ssalaria@ucsd.edu

USA 